\title{
The Impact of Climate Change on the Viticultural Suitability of Maipo Valley, Chile
}

\author{
Megan Mills-Novoa ${ }^{1}$, Philippo Pszczólkowski², Francisco Meza ${ }^{3}$ \\ ${ }^{1}$ Fulbright Research Fellow, Centro Interdisciplinario de Cambio Global, Pontificia Universidad Católica \\ de Chile, Avenida Vicuña McKenna 4860, Macul, Santiago, Chile \\ ${ }^{2}$ Departamento de Fruticultura y Enología, Pontificia Universidad Católica de Chile, Avenida Vicuña \\ McKenna 4860, Macul, Santiago, Chile \\ ${ }^{3}$ Centro Interdisciplinario de Cambio Global, Departamento de Ecosistemas y Medio Ambiente, Pontificia \\ Universidad Católica de Chile, Avenida Vicuña McKenna 4860, Macul, Santiago, Chile \\ *Corresponding Author (email: mmillsnovoa@email.arizona.edu)
}

\begin{abstract}
This study uses the case of the Maipo Valley in Chile to examine how climate change will affect viticultural suitability. Using a GIS analysis of topographic, soil, land use and climate data, a baseline assessment of viticultural suitability in the Maipo Valley was performed. The impact of climate change on viticultural suitability was modeled by overlaying downscaled Global Circulation Model temperature data for two emission scenarios. The findings of this study suggest that the capacity of vineyard managers in the Maipo Valley to cultivate high quality traditional grape varietals from cooler grape maturity classes may be limited in the future.
\end{abstract}

Key words: Central Chile, Climate Change, GIS, Viticultural Suitability, Wine 
Within the last few decades there has been a growing consensus that anthropogenic greenhouse gas emissions have, and will increasingly, have a significant impact on the earth’s climate (IPCC 2007; 2014). Viticulture, due to the narrow climatic range of high quality wine grape production, is one of the agricultural sectors most vulnerable to the impacts of climate change. For this reason, it is critical to understand how viticultural suitability could be affected by changing climatic conditions in wine-growing regions under different climate change scenarios.

Recent research has projected that viticultural zones will shift 150-300km pole ward by 2049 and an additional 12-25km pole ward by 2099 under mid-range emission scenario projections (Jones 2007). Increases in mean annual temperature are the driver of these shifts and warming trends have already been detected within many wine-growing areas (Fraga et al. 2012; Koufos et al. 2014). Jones (2005) found that since 1950 there has been a $1.3^{\circ} \mathrm{C}$ and $1.4^{\circ} \mathrm{C}$ increase in winter and summer temperatures respectively in 27 high-quality wine producing regions. Hannah et al. (2013) found that there will be a 25 percent to 73 percent decline in area suitable for viticulture by 2050 in five major wine producing regions globally.

While the majority of the literature documents climate change impacts at a larger scale of resolution in an effort to generate global or country level synthesis, far less work has been done to assess the variability present at a finer scale of resolution. In an effort to develop a methodological framework that offers results at a scale that is useful to practitioners and policymakers, we focused our study at the regional scale. Additionally, few studies have focused on the impact of climate on viticulture, an economically important industry within Chile. This project assesses the future impacts of climate change on the viticultural suitability of the Maipo 
Valley, contributing to the ongoing discussion of appropriate adaptation strategies for this economically important region, which produces 12 percent of all wine in Chile (SAG 2014).

Soil and climate are the main elements that have been used to define the concept of “terroir" (Vadour 2002) and characterize the viticultural suitability of a region. Among these elements, climate is the most critical factor in determining the ability of a region to produce high quality wine grapes (Seguin and De Cortazar 2005). Viticultural production is broadly limited to the growing season isotherms of $12-22^{\circ} \mathrm{C}$ (Jones 2006). Additionally, large differences between daytime and nighttime temperatures favor the concentration of solutes and accumulation of sugars and acids that facilitate the cultivation of high quality wine grapes. Optimal grape growing locations such as central Chile have large diurnal temperature ranges of 15 to $20^{\circ} \mathrm{C}$.

Recognizing the importance of temperature, a wide number of bioclimatic indices have been proposed utilizing temperature as the most relevant variable for characterizing grapegrowing suitability (Winkler et al. 1974; Huglin 1978; Gladstones 1992). These indices have been applied to define viticultural regions at a global or country level scale as in the case of Chile (Tonietto and Carbonneau 2004, Merlet et al. 1987). These bioclimatic indices, which match climatic characteristics to the capacity of an area to produce grape varietals with different climatic requirements, offer an important tool in assessing the impact of climate change on winegrowing regions.

Beyond the general pole ward shift of viticultural zones and broad warming trend, the magnitude of climate change impacts on viticultural suitability will differ by region. White et al. (2006) project that, within the U.S., premium wine grape production will decline by 81 percent corresponding to decreased productivity in current wine producing regions. Wine growing regions in Australia are also expected to significantly contract due to projected warming and 
have a limited capacity to shift, because many of these areas currently reside in southernmost Australia and will be unable to shift further pole ward (Hall and Jones 2008). Harvest dates within Europe are already occurring 6-25 days earlier, reflecting the strong relationship between phenological timing and warming (Jones 2005) and further studies have indicated a north and north-westerly shift in wine growing regions within Europe due to climate change (Moriondo et al. 2013).

Despite Chile’s role as the eighth largest producer of wine and fifth largest exporter of high quality wine internationally, few studies have looked at the impact of climate change on wine production in Chile. Montes et al. (2012) characterized the climatic potential for viticulture in the Central Valley but did not integrate an analysis of climate change impacts. Central Chile is particularly vulnerable to the compounding impacts of water scarcity and elevated temperature due to climate change making an analysis of climate change impacts on wine suitability critical for regional climate change adaptation planning and future scholarship. Warming trends have already begun to impact Chilean wine growing regions. Warming rates between 1.3 to $2.0^{\circ} \mathrm{C}$ between 1933-1992 have been detected by several weather stations within Chile (Rosenbluth et al. 1997). More recent data has shown that temperature trends are spatially heterogeneous with $.2^{\circ} \mathrm{C}$ per decade cooling at coastal stations and $.25^{\circ} \mathrm{C}$ warming in the Andes (Garreaud and Falvey 2009).

The purpose of this study is to assess the current and future viticultural suitability of the Maipo Valley in the Central Valley of Chile. Soil, topographic, land use and historical weather data were used to create a baseline assessment. Two IPCC emissions scenarios and corresponding Global Circulation Models (GCMs) were then used to assess future viticultural suitability for three 30 year normals. Ultimately, this project assesses the future impacts of 
climate change on the viticultural suitability of the Maipo Valley, contributing to the discussion of appropriate adaptation strategies for this region that has experienced a tremendous 260 percent growth in the extent of vineyards since 1997 (SAG 2013).

The study seeks to integrate and synthesize geographic and biophysical data at the scale of one Denomination of Origin, the legal delineation of a wine-growing region, and the broader, corresponding water basin in order to provide an analysis at a level that is relevant for practitioners and policymakers. Additionally, this study builds on the methodology of assessing composite viticultural suitability through the integration of topographic, soil, land use and temperature data and integrates this assessment into a characterization of projected climate change impacts on the viticultural conditions within the region. The similarities between Maipo Valley and other high quality wine producing regions such as California, Australia, and South Africa, make this study highly relevant to understanding the vulnerability of globe’s most significant wine-producing regions to a changing climate.

\section{Materials and Methods}

Study Area

The Chilean viticultural area of Maipo Valley was included in this study as delineated according to the Chilean wine appellation of origin system (Figure 1). Maipo Valley is located in the Central Valley of Chile between latitudes $32^{\circ} 55^{\prime}$ and $34^{\circ} 15^{\prime} \mathrm{S}$ and encompasses the metropolitan area of Santiago. There are three distinct regions within Maipo Valley: Alto Maipo in the foothills of the Andes, Central Maipo on the valley floor and Coastal Maipo. Within Maipo Valley 12,679 ha are cultivated for viticultural purposes with the principal varietals cultivated being Cabernet Sauvignon (52.2 percent of surface), Merlot (9 percent), Syrah (8.5 percent), Chardonnay (7.5 percent), Carménère (7 percent), Sauvignon Blanc (5.3 percent), and 
Cabernet Franc (2.1 percent) (SAG 2011). Vineyards are generally cultivated with the use of irrigation with approximately 60 percent of all vineyards relying on surface water for irrigation and the remaining 40 percent utilizing groundwater. This region is characterized by a Mediterranean climate with maximum temperatures ranging from $25^{\circ} \mathrm{C}$ to $35^{\circ} \mathrm{C}$ during the growing season (October-April) and with large diurnal temperature ranges throughout the year. Thermal accumulation is around 1,550 degree-days (Merlet et al. 1987). Mean annual precipitation increases towards the Andes varying from $456 \mathrm{~mm}$ (Buin) to $736 \mathrm{~mm}$ (Puente AltoPirque) though 80 percent of precipitation occurs in winter.

Within this study, the entire Maipo River basin in addition to the Maipo Valley denomination of origin was included because vineyard development has continued to extend beyond the formal Maipo Valley Denomination of Origin. Additionally, this study sought to assess future viticultural suitability and therefore areas within the river basin not currently under cultivation were considered, because these areas may become potential grape growing sites based on projected climate change impacts. All analyses were done at the scale of the Maipo River basin below 2000m (to exclude mountainous areas) to capture future potential viticultural zones.

Topographic Suitability

In order to characterize the baseline viticultural suitability of Maipo Valley, a multi-stage Geographic Information System (GIS) analysis was performed, incorporating factors related to topography, soils, land use, and climate. To establish an understanding of the geographic features of existing individual vineyard sites, a comprehensive GIS database of vineyard locations was created (Jones et al. 2004). The survey of Maipo Valley vineyard sites was conducted using Google Earth imagery and aerial photography. Vineyard locations were then 
verified through site visits and the use of a Global Positioning System (GPS). The locational data gathered, as well as conversations with wine makers and vineyard managers, was used to define the topographical characteristics of ideal sites for grape growing in the valley (Jones et al. 2004).

The topographic suitability was assessed through the use of a 30-meter resolution digital elevation model (DEM). The entire extent of the Metropolitan Region, which encompasses Maipo Valley, was then categorized for the most advantageous slope, elevation, and solar radiation. The composite topographic viticultural suitability was constructed through a multilayer, topographically driven potential site analysis using ArcGIS with class rankings given to the respective topographic factors characterized in each grid (Table 1). The elevation ranking was determined through the use of in-field observations as well as the distribution of the average elevation of current vineyards as determined through the initial survey of vineyard sites. The high elevation threshold reflects the presence of high-quality vineyards in the foothills of Andes, residing in the eastern extent of the region. Slopes were categorized into five classes (Table 1). A calculation of solar radiation was used instead of aspect in order to account for the seasonal variation in solar declination and azimuth. A solar radiation index was calculated every 30 days at two-hour intervals during the growing season (October - April) using the ArcGIS spatial analysis solar radiation tool. Solar radiation values were reclassified based on the statistical distribution of radiation values (Santibañez 1992; Jones et al. 2004). The three separate suitability grids were then summed to create a single topographic suitability layer.

\section{Soil Suitability}

To analyse the soil suitability of the Maipo Valley, data from Centro de Información de Recursos Naturales (CIREN) was used. Site suitability was analysed based on four soil 
properties: depth to bedrock, total available water, $\mathrm{pH}$, and drainage (Margarey et al. 1998). An average value for all four properties was established for each soil group.

Drainage is widely regarded as the most important factor in determining vine success and is influenced by variables such as texture, depth, slope, and aspect (Cass 1999). Chilean soil surveys present drainage classifications using six classifications ranging from very poorly drained to excessively drained. Soil groups were characterized by their drainage class and given corresponding suitability rankings (Table 2). In dry growing regions, such as the Maipo Valley, the depth to bedrock indicates the vine’s ability to cope with dry periods (Dry and Smart 1988). Soil groups were characterized by their depth and given a corresponding suitability ranking.

Total available water (TAW) is a property that factors in both the available water holding capacity as well as the effective root depth of soil and indicates the capacity of vines to tolerate moderate drought. The mean available water holding capacity for each soil group was calculated and then weighted by the percentage of each component per map unit. Soil groups were characterized by their respective class ranking (Cass et al. 2002). Soil pH is an indication of soil fertility and nutrient balance. A mean value was calculated for each soil group and then weighted by the percentage of each component per map unit. Three classes were established with ideal vineyard soils having a pH between 6-9 (Cass et al. 2002).

The four soil property suitability grids were then were combined using a weighted sum with drainage being given the greatest weight (40 percent) and the other factors weighted equally (20 percent) reflecting the relative importance of these soil properties in determining vine success (Jones et al. 2004). A final soil suitability composite grid was produced from the weighting of the four soil properties.

\section{Land Use Suitability}


Within the Maipo Valley, land use is a key determinant in assessing viticultural potential. Santiago, which is adjacent to the Maipo Valley Denomination of Origin, is an expanding metropolitan area and formerly agricultural land has been converted to land uses which are not conducive to viticultural production (residential, industrial, commercial etc.). The urbanized surface area of Santiago and outlying towns was extracted from the data set since these areas no longer have viticultural potential.

\section{Baseline Climatic Suitability}

To assess climatic suitability, a composite climate model was generated using three factors: varietal suitability, irrigation need and risk to extreme weather events. Temperature data from eight weather stations within Maipo Valley with an average 18 year record length were used to calculate all variables. Weather stations within Santiago were excluded from the study due to urban heat island impacts and low viticultural suitability in these areas. Station temperature data was corrected using a factor of $.6^{\circ} \mathrm{C}$ per $100 \mathrm{~m}$ (equivalent to the mean temperature lapse rate) to better represent climatic conditions of vineyards residing at higher elevation but within the same comuna as the station (Gladstones 2011). If no vineyards were located within the comuna of a given weather station then the average vineyard elevation within the total study area was used. Temperature data was only corrected for elevation for one weather station (Rungue Embalse), while all other weather stations were located at the approximate elevation of the average vineyard within that area.

To calculate varietal suitability, biologically effective degree days (BEDD) were calculated in order to estimate the phenological fit of grape varietals to model climatic conditions within Maipo Valley. The use of a BEDD index enables sites to be characterized by climate maturity classes that categorize grape varietals by optimal heat summation ranges. The BEDD 
index developed by Gladstones (2011) was used for climate maturity class designation. BEDD calculates heat summation while incorporating an adjustment for diurnal temperature range and a day length correction factor (Hall and Jones 2010; Gladstones 2011)

$$
\sum_{\text {October } 1}^{\text {April } 30} \min \left[\max \left(\left[T_{\max }+T_{\text {min }}\right] / 2-10,0\right) K+T R_{\text {adj }}, 9\right]
$$

where

$$
T R_{a d j}=\left\{\begin{array}{c}
0.25\left[T_{\max }-T_{\min }-12\right],\left[T_{\max }-T_{\min }\right]>12 \\
0,10<\left[T_{\max }-T_{\min }\right]<12 \\
0.25\left[T_{\max }-T_{\min }-10\right],\left[T_{\max }-T_{\min }\right]<10
\end{array}\right.
$$

and $\mathrm{K}$ is an adjustment for latitude/day length and was calculated according to Gladstones (2011). BEDD values were then interpolated using inverse distance weighting (IDW) function within ArcGIS because this interpolation method produced the lowest level of error when compared to kriging and other interpolation techniques. BEDD values were then reclassed by corresponding grape variety climate maturity classes (Jones 2006; Gladstones 2011).

Irrigation need was calculated for the study area with the use of the Hargreaves evapotranspiration equation, which was selected because of data availability within the region (Allen et al. 1998)

$$
E T_{0}=0.0023\left(T_{\text {mean }}+17.8\right) \sqrt{\left(T_{\max }-T_{\min }\right)} R_{a}
$$

where $R_{a}$ is extraterrestrial radiation $\left(\mathrm{MJ} \mathrm{m}^{-2} \mathrm{day}^{-1}\right)$. Within this study, relative evapotranspiration levels within the basin are most important when estimating relative irrigation need. Evapotranspiration values for weather stations were interpolated using IDW and reclassed into three suitability classes according to the relative rate of evapotranspiration. 
Risk was calculated by summing the number of days with extreme heat events of maximum temperatures above $35^{\circ} \mathrm{C}$ (White et al. 2006). Within Maipo Valley, frost damage is not a significant concern and therefore extreme heat was the only climate risk value considered. Days of extreme heat were interpolated using IDW and values were reclassed according to relative heat risk. Areas that experienced more than 3 days with maximum temperatures exceeding $35^{\circ} \mathrm{C}$ were ranked as being high-risk areas.

Chilling hours or hours with temperatures below $7^{\circ} \mathrm{C}$ were also assessed for both baseline and projected temperature records. Due to the relatively low chilling hour requirement of grapevines and the high diurnal temperature range in Maipo Valley, chilling hours was not a significant limiting factor and was not included. Composite Baseline Viticultural Suitability

The four site factors-topography, soil, land use, and climate were then combined by summing the composite suitability rasters. The composite suitability grid was then masked with the climate maturity class grid to create a final data set that depicts the relative viticultural suitability by climate maturity class.

\section{Projected Climatic Suitability}

Within this study, the bias-correction and spatial downscaling method of Wood et al. (2004) was used, because it is quantitatively efficient and performed well when applied to studies that downscaled extended GCM simulations for impact analyses (Hayhoe et al. 2004; Maurer and Duffy 2005; Maurer et al. 2007). This method is an empirical statistical technique in which monthly precipitation and temperature output from a given GCM is downscaled using quantilebased mapping (Panofsky and Brier 1968) of the probability density functions for a monthly GCM temperature onto those of gridded observed data. Temperature data from all eight weather 
stations was downscaled for scenario A1B and B1 using seven GCMs. The A1B emissions scenario assumes "balanced” growth and land use changes whereas the B1 emission scenario assumes a world development path the "favors efficiency of resource use and 'dematerialization' of economic activities” (IPCC 2000).

The seven GCMs were chosen because they were representative of a range of distinct GCMs suited to Southern South America, allowing for an analysis of the range of uncertainty within the downscaling process (Meehl et al. 2007; Marengo et al. 2009). The GCMs and related IPCC AR4 emission scenarios used in the analysis were chosen because the majority of analysis was conducted prior to the release of the AR5 emission scenarios. Knutti and Sedlacek (2013) found that the IPCC AR5 climate models were very similar to the AR4 models with consistent temperature and precipitation patterns. The AR5 Representative Concentration Pathways (RCPs), are significantly different that the AR4 emission scenarios in that they represent a wider range of possible future outcomes. However, in the scope this study, we sought to examine the impact of mid-range emission scenarios on viticulture, and therefore the use of AR4 emission scenarios still allows for a robust analysis of these impacts.

An average temperature was calculated by averaging the outputs of the seven GCMs for a given month. Daily values for GCMs are generated by randomly selecting historical months and creating a daily record that mirrors historical temperature variation but is rescaled using an additive factor according to projected monthly average temperatures (Wood et al. 2004). Minimum and maximum daily temperatures were calculated by importing historical daily maximum and minimum temperatures into the downscaling model.

Based on the daily minimum, maximum, and average temperatures that were calculated through the downscaling process, the climatic variables of evapotranspiration, BEDD, and days 
with maximum temperatures exceeding $35^{\circ} \mathrm{C}$ were subsequently calculated for comparison with historical values. These values were calculated for three 30-year normal: 2010-2040, 2040-2070 and 2070-2100 under two IPCC emission scenarios. Projected climate variables were interpolated using IDW and rasters were reclassed according to the suitability rankings and climate maturity classes detailed earlier.

\section{Composite Projected Viticultural Suitability}

The four site factors-topography, soil, land use, and projected climate were then combined for both the scenario A1b and B1 downscaled data over the three climate normals by summing the composite suitability grids for each factor according to their individual grapegrowing influence as detailed above. The composite suitability grids was then masked by the corresponding climate maturity class grid to create a final data set that depicts the relative viticultural suitability of sites by climate maturity class for both climate change scenarios for all three climate models and a control. Based on these rasters, land area data was extracted in order to infer the changes in grape growing suitability zones within Maipo Valley. The methodological framework used in this study is represented schematically in Figure 2.

\section{Results}

\section{Baseline Viticultural Suitability}

In the Maipo Valley denomination of origin, the vineyards surveyed encompassed 96.44 sq. km across 15 comunas, which are regional sub-division units within Chile (Figure 1). Two hundred and twenty-two vineyard tracts were surveyed. The average elevation of vineyards was 480m and vineyards were found at elevations ranging from 123-835m. Vineyard slopes ranged from 26.8 percent to essentially flat with an average slope of 5.7 percent. The elevation and slope values of vineyards were clustered by region with many of the high elevation, high slope 
vineyards residing in the foothills of the Cordillera. Within the Maipo Valley, 69.8 percent of all land was found to have high or intermediate-high topographic suitability with only 23.6 percent of all land being categorized as having low or intermediate-low suitability (Figure 3). Much of the land that was topographically unsuitable was found in the steep foothills of the Cordillera. 86.9 percent of the Maipo Valley was found to have high or intermediate-high soil suitability (Figure 3). The highest scoring soils were found on the valley floor and among the low-lying hills. 665.8 sq. kilometers were categorized as having no viticultural suitability due to urban land use (Figure 3).

The topographic, soil and land use suitability datasets were then summed to produce a baseline scale of suitability. 8.6 percent of the Maipo Valley was classified as having high viticultural suitability, 45.9 percent with intermediate-high viticultural suitability, 27.9 percent with intermediate suitability and 17.6 percent with intermediate-low or low viticultural suitability (Figure 3).

Climatically, no portion of the study area was found to have heat summation values outside of the suitable range for maturing high quality wine grapes though there was a significant range of climate maturity classes represented. 12.4 percent of Maipo was designated as Class V, 33.8 percent as Class VI, 38.5 percent as Class VII, and 15.33 percent as Class VIII (Figure 3). The hotter classes were found in the northern, more arid portion of the valley with cooler classes found in the eastern and western borders of the valley, where higher elevation vineyards enjoy cooler temperatures as well as the cooling effect of the nearby coast. Across climate maturity classes fairly consistent distributions of high to low suitability rankings were found. Projected Viticultural Suitability 
The projected climatic analysis found across scenarios and models that temperatures increased by the mid-century (Table 3). As related to viticultural suitability, climate maturity classes became more prevalent through time and in both scenarios (Figure 4). Among the A1B scenario, which is the more severe scenario, the east/west and north/south temperature gradient is still visible in the early scenarios but becomes classified as uniformly climate maturity class IX. Scenario B1 as well as the control initially underestimated the heat summation occurring in the eastern portion of the valley but in B1 hotter climate maturity classes progressively become more prevalent through time, though never reaching the severity modelled in A1B (Figure 4).

Beyond shifting climate maturity class suitability through time, a subtle change in overall viticultural suitability was observed (Table 4). This worsening viticultural suitability reflects the impact of increased temperatures on irrigation need and risk due to extreme high temperature events both of which are suitability parameters.

\section{Discussion}

The projected viticultural suitability models show a consistent trend toward warmer climate maturity classes, suggesting that the ability of vineyard managers to produce high-quality grapes from cooler climate maturity classes may be limited in the future. BEDD is not ideal for assessing if a region is unsuitable for viticultural production due to high temperatures because vineyard managers may choose to harvest varietals earlier when the necessary heat summation has occured (Hall and Jones 2010). The quality of grapes harvested earlier may be reduced, however, because phenological development can be rapid and produce unbalanced wines due to earlier sugar ripeness and loss of acidity through respiration (Jones et al. 2004; Keller 2010). Though methodologically different, the results of this study are consistent with Webb et al. (2007) and Hall and Jones (2008) suggesting that harvests are likely to occur earlier and seasons will be shortened due to warming. Additionally, within this study the analysis of irrigation need 
and heat risk does suggest that the future capacity of Maipo Valley vineyards to produce high quality grape varietals from intermediate climate maturity classes (including Cabernet Sauvignon) may be limited.

Jones (2005) found that many grape growing regions are at, or near, their optimal growing season temperature. The baseline assessment of grape variety maturity classes within the Maipo Valley suggests that the same situation exists within the study area where the premium cultivars Cabernet Sauvignon (class VI), Carmenére (class VII), and Merlot (class V) are grown in areas with growing season heat accumulation that are close to ideal for their corresponding climate maturity class. Vineyard managers may be able to adapt to some of these climatic shifts through the employment of adaptive management strategies, the utilization of varietals suited to warmer climates and the establishment of vineyards at higher elevation sites. Fraga et al. (2012) suggest that adaptation strategies within viticulture can be focused on shortterm impacts by addressing specific threats through crop management practices or longer term impacts through varietal and land allocation changes.

In addition to the progressively higher average temperatures modeled for this region, a significant increase in the occurrence of extreme heat events could have an impact on the viticultural suitability of this valley. Temperatures above $30^{\circ} \mathrm{C}$ have been found to reduce berry size and weight (Hale and Buttrose 1974) and stop metabolic processes and sugar accumulation altogether (Kriedemann and Smart 1971; Coombe 1987). Hall and Jones (2010) found that BEDD, as a suitability index produces actual daily mean temperatures closer to reality though due to its $9^{\circ} \mathrm{C}$ cap is less sensitive to large increases in temperature. Our inclusion of extreme heat as a suitability variable allowed us to capture large temperature increases as well as retain a robust index for characterizing viticultural suitability. An increase in the frequency and severity 
of extreme heat events could adversely affect the quality of grapes produced in Maipo Valley, increasing the risk associated with cultivation.

A climatic factor not incorporated into this study is the potential impact of climate change on precipitation within this region. The majority of vineyards within Maipo Valley are irrigated, mitigating acute drought impacts on vines. Meza et al. (2012), projected that precipitation levels will decrease in the Maipo Basin by the end of the century while irrigation needs will likely increase, causing increased stress on water resources. The issue of water scarcity within the Maipo, which is currently in the midst of a prolonged drought, will become increasingly important as a resource constraint for viticulturalists and other agricultural users within the Maipo River basin.

This study has been constrained by the relatively limited temperatures records available for Maipo Valley. Many records are limited in timescale when compared to temperature data records available in other wine growing regions internationally. Since historic temperature data is used to downscale GCMs, this lack of data availability reduces the resolution of these models. Additionally, regression-based statistical downscaling has been found to increase the uncertainty of the constituent global circulation models and greenhouse gas emissions that comprise them. Chen et al. (2011) suggest that climate change impact studies should include more then one downscaling methods in order to better represent the uncertainty inherent within downscaling. Within this study, we chose climate change models that were best suited to the Southern Cone in order to increase the robustness of our findings as well as downscaling methodology that was well suited to our research objectives (Wood et al. 2004; Hayhoe et al. 2004; Maurer and Duffy 2005; Maurer et al. 2007). To further improve our analysis, a future, productive avenue of study 
would be to use additional downscaling methodologies in modeling climate change impacts on viticulture within the Maipo Valley in order to better quantify uncertainty within our analysis.

\section{Conclusion}

This study utilized topographic, soil, land use and historical climate data to analyse the baseline viticultural suitability of the Maipo Valley in Central Chile. Historical data was then used to downscale Global Circulation Models for scenario A1b and B1 for three 30-year normals spanning from 2010 to 2100 . This projected climate data was utilized to analyse projected viticultural suitability. The results of this study indicate that there is a significant trend toward hotter climate maturity classes within Maipo Valley. This suggests that the capacity of wine producers to cultivate high-quality grapes from traditional varietals may become increasingly limited if no adaptation measures are taken. This research opens new opportunities for comparative regionally focused studies, providing a broader understanding of the commonalities and differences in climate change impacts on the viticultural suitability of prominent winegrowing regions internationally. Additionally, despite the inherent uncertainty in climate change analyses such as this one, studies of this nature reinforce the importance of investing in research relating to adaptive vineyard management practices and resilient varietals.

\section{Acknowledgements}

The authors appreciate the contribution of David Poblete and Eduardo Bustos from the Centro de Cambio Global for their help with the downscaling process and trouble-shooting as well as Anna and Zack Steel for assistance with programming and cartography respectively. Thanks also go to the Fulbright Commission-Chile for their support of this work. This work was partially supported by Fondecyt Grant 1120713 during the analysis stage and by the Inter-American Institute for Global Change Research (IAI, project CRN3056, which is supported by the US National Science Foundation grant GEO-1128040). Lastly, the authors would like to thank the UA SGD's Writing Workshop peer group for their guidance and support. 


\section{References}

Allen, R.G., L.S. Pereira, D. Raes, and M. Smith. 1998. Crop evapotranspirationGuidelines for computing crop water requirements. FAO irrigation and drainage paper 56.

Cass, A. 1999. What soil factors really determine water availability vine?

Australian Grapegrower and Winemaker Annual Technical Issue: 95-97.

Cass, A., D. Hansen, and A. Dowley 2002. Grape Performance and Soil Conditions. In Sustainable viticulture production: optimizing soil resources. ed. A. Cass, 5-15.

Chen, J., F.P. Brissette, and R. Leconte. 2011. Uncertainty of downscaling method in quantifying the impact of climate change on hydrology. Journal of Hydrology 401: 190202.

Coombe, B.G. 1987. Influence of temperature on composition and quality of grapes. Proceedings of the Symposium on Grapevine Canopy and Vigour Management. Acta Horticulturae 206: 23-35.

Dry, P.R. and R.E. Smart 1988. Vineyard Site Selection. In Viticulture. eds. B.G. Coomber and P.R. Dry. Winetitles: Adelaide, SA, Australia.

Fraga, H., Malheiro, A.C., Moutinho-Pereira, J., and J.A. Santos. 2012. An overview of climate change impacts on European viticulture. Food and Energy Security 1(2): 94-110.

Jones, G.V., N. Sneed, and P. Nelson. 2004. Modelling viticultural landscapes: a GIS analysis of the terroir potential in the Umpqua Valley of Oregon. Geoscience Canada 31(4): 167-178.

Jones, G.V. 2005. Climate change and global wine quality. Climatic Change 73(3): 319-343.

Jones, G.V. 2006. Climate change and wine: observations, impacts and future implications. Wine Industry Journal 21(4): 21-26.

Jones, G.V. 2007. Climate change and the global wine industry. Proceedings of the 13th Australian Wine Industry Technical Conference: 1-8.

Garreaud, R.D. and M. Falvey. 2009. The coastal winds off western subtropical South America in future scenarios. International Journal of Climatology 29(4): 543-554.

Gladstones, J. 1992. Viticulture and Environment. Winetitles: Adelaide, Australia.

Gladstones, J. 2011. Wine, Terroir and Climate Change. Wakefield Press: Kent Town, Australia.

Hall, C.R. and M.S. Buttrose. 1974. Effect of temperature on ontogeny of berries of Vitisvinifera L. cv. Cabernet Sauvignon. Journal of the American Society of Horticultural Science 99: 390-394.

Hall, A. and G.V. Jones 2008. Effect of potential atmospheric warming on temperature-based indices describing Australian winegrape growing conditions. Australian Journal of Grape and Wine Research 15(2): 97-119.

Hall, A. and G.V. Jones. 2010. Spatial analysis of climate in winegrape-growing regions in Australia. Australian Journal of Grape Wine Research 16: 389-404.

Hannah, L., P. Roehrdanz, M. Ikegami, A.V. Shepherd, M.R. Shaw, G. Tabor, L. Xhi, P. Marquet, and R. Hijmans. 2013. Climate change, wine, and conservation. PNAS 110 (17): 6907-6912.

Hayhoe, K., D. Cayan, C.B. Field, P.C. Frumhoff, E.P. Maurer, N.L. Miller, S.C. Moser, S.H. Schneider, K.N. Cahill, E.E. Cleland, L. Dale, R. Drapek, R.M. Hanemann, L.S. Kalkstein, J. Lenihan, C.K. Lunch, R.P. Neilson, S.C. Sheridan and J.H. Verville. 2004. 
Emissions pathways, climate change, and impacts on California. Proceedings of the National Academy of Sciences 101(12): 422-427.

Huglin, P. 1978. Nouveau mode d'evaluation des possibilities héliothermiques d'unmilieu viticole (New methods for evaluation of thermal solar for viticulture). Comptes rendus de l'académie d'agriculture de France 64: 1117-1126.

IPCC. 2000. Emission scenarios: Special report on emissions scenarios. eds. N. Nakicenovic and R. Swart. Cambridge University Press: Cambridge, UK.

IPCC. 2007. Climate change 2007: the physical science basis. Eds. S. Solomon, D. Qin, M. Manning, Z. Chen, M. Marquis, K.B. Averyt, M. Tignor and H.L. Miller. Cambridge University Press: Cambridge, UK

IPCC. 2014 Climate change 2014: Impacts, Adaptation, and vulnerability. Contribution of working group II to the Fifth Assessment Report of the Intergovernmental Panel on Climate Change. Eds. Field, C.B., V.R. Baroos, D.J. Dokken, K.J. Mach, M.D. Mastrandrea, T.E. Bilir, M. Chatterjee, K.L. Ebi, Y.O. Estrada, R.C. Genova, B. Girma, E.S. Kissel. A.N. Levy, S. MacCracken, P.R. Mastrandrea, and L.L. White. Cambridge University Press: Cambridge, United Kingdom and New York, NY.

Keller, M. 2010. Managing grapevines to optimise fruit development in a challenging environment: a climate change primer for viticulturalists. Australian Journal of Grape and Wine Research 16: 56-69.

Koufos G, T, Mavromatis, S. Koundouras, N. Fyllas, and G. Jones G. 2014. Viticulture-Climate relationships in Greece: the impacts of recent climate trends on harvest date variation. International Journal of Climatology 34: 1445-1459.

Knutti, R. and J. Sedlacek. 2013. Robustness and uncertainities in the new CMIP5 climate model projects. Nature Climate Change 3: 369-373.

Kriedemann, P.E. and R.E. Smart. 1971. Effects of irradiance, temperature and leaf water potential on photosynthesis of vine leaves. Photosynthetica 6: 6-15.

Marengo, J.A., R. Jones, L.M. Alves, and M.C. Valverde. 2009. Future changes of temperature and precipitation extremes in South America as derived from the PRECIS regional climate modelling system. International Journal of Climatology 29(15): 2241-2255.

Margarey, R.D., R.C. Seem, and S.D. DeGloria. 1998. Prediction of vineyard site suitability. Grape Research News 9(1): 1-2.

Maurer, E.P. and P.B. Duffy. 2005. Uncertainty in projections of stream-flow changes due to climate change in California. Geophysical Research Letters 32: L03704.

Maurer, E.P., L. Brekke, T. Pruitt, and P.B. Duffy. 2007. Fine-resolution climate change projections enhance regional climate change impact studies. Eos, Transactions American Geophysical Union 88: 504.

Meehl, G.A., T.F. Stocker, W.D. Collins, P. Friedlingstein, A.T. Gaye, J.M. Gregory, A. Kitoh, R. Knutti, J.M. Murphy, A. Noda, S.C.B. Raper, I.G. Watterson, A.J. Weaver and Z.-C. Zhao (2007) Global Climate Projections. In: Climate Change 2007: The Physical Science Basis. Contribution of Working Group I to the Fourth Assessment Report of the Intergovernmental Panel on Climate Change. Eds. Solomon, S., D. Qin, M. Manning, Z. Chen, M. Marquis, K.B. Averyt, M. Tignor and H.L. Miller. Cambridge University Press, Cambridge, United Kingdom and New York, NY, USA.

Merlet, H., H. Castillo and F. Santibañez. 1987. Áreas isoclimáticas para la vitivinicultura en la zona central de Chile. Primer Simposio internacional sobre la denominación de origen de productos vitivinícolas en América latina: La Serena, Chile, 
211-227

Meza, F., Wilks, D.S., L. Gurovich and N. Bambach. 2012. Impacts of climate change on irrigated agriculture in Maipo Basin, Chile: reliability of water rights and changes in the demand for irrigation. Journal of Water Resource Planning and Management 138: 421-430.

Montes, C., J.F. Perez-Quezada, A. Peña-Neira and J. Tonietto. 2012. Climatic potential for viticulture in Central Chile. Australian Journal of Grape and Wine Research 18(1): 2028.

Moriondo, M., G.V. Jones, B. Bois, C. Dibari, R. Ferrise, G. Trombi, and M. Bindi. 2013. Projected shifts of wine regions in response to climate change. Climatic Change 199: 825-839.

Panofsky, H.A. and G.W. Brier. 1968. Some applications of statistics to meteorology. Pennsylvania State University: University Park, PA, 224.

Rosenbluth, B., G. Casassa, and H. Fuenzalida. 1997. Recent temperature variations in southern South America. International Journal of Climatology 17: 67-85.

Santibañez, F. 1992. El clima como regulador del potencial vitivinícola. International seminar: La vitivinicultura del future: Talca, Chile, pp. 9-17.

Seguin, B. and I.G. De Cortazar. 2005. Climate warming: consequences for viticulture and the notion of "terroirs" in Europe. Acta Horticulturae 689(1): 61-69.

Servicio Agrícola y Ganadero. 2011. Servicio Agrícola y Ganadero vineyard registry website (Chilean government) http://www.sag.cl/ambitos-de-accion/catastro-viticola (last accessed 24 March 2015).

Servicio Agrícola y Ganadero. 2013. Servicio Agrícola y Ganadero vineyard registry website (Chilean government) http://www.sag.cl/ambitos-de-accion/catastro-viticola (last accessed 24 March 2015).

Servicio Agrícola y Ganadero. 2014. Servicio Agrícola y Ganadero vineyard registry website (Chilean government) http://www.sag.cl/ambitos-de-accion/catastro-viticola [last accessed 24 March 2015).

Tonietto, J. and A. Carbonneau. 2004. A multicriteria climatic classification system for grape growing regions worldwide. Agricultural and Forest Meteorology 124: 81-97.

Vadour, E. 2002. The quality of grapes and wine in relation to geography: notions of terroir at various scales. Journal of Wine Research 12(2): 95-109.

White, M.A., N.S. Diffenbaugh, G.V. Jones, J.S. Pal, and F. Giorgi. 2006. Extreme heat reduces and shifts United States premium wine production in the $21^{\text {st }}$ century. Proceedings of the National Academy of Science 103(30): 11217-11222.

Webb, L.B., P.H. Whetton, and E.W.R. Barlow. 2007. Modeled impact of future climate change on the phenology of winegrapes in Australia. Australian Journal of Grape Wine Research 13: 165-175.

Winkler, A.J., J.A. Cook, W.M. Kliewer, and L.A. Lider. 1974. General viticulture. University of California Press: Berkeley, California, USA.

Wood, A.W., L.R. Leung, V. Sridhar, and D.P. Lettenmaier. 2004. Hydrologic implications of dynamical and statistical approaches to downscaling climate model outputs. Climatic Change 62: 189-216.

MEGAN MILLS-NOVOA is a graduate student in the School of Geography and Development at the University of Arizona, Tucson, AZ 85721. E-mail: mmillsnovoa@email.arizona.edu. Her 
research interests include Andean agricultural systems, climate change adaptation and mixed method approaches.

FRANCISCO MEZA is a professor in the Facultad de Agronomia e Ingeniería Forestal and the Director of the Centro de Cambio Global at the Pontificia Universidad Catolica de Chile, Santiago, CHILE. Email: fmeza@uc.cl. His research interests include impacts of global change on agriculture, forest and water resources and the development of adaptation strategies for these sectors.

PHILIPPO PSZCZOLKOWSKI is a professor of enology in the Facultad de Agronomia e Ingeniería Forestal at the Pontificia Universidad Catolica de Chile, Santiago, CHILE. Email: philippo@uc.cl. His research interests include Chilean viticulture and enology.

\section{Figure Captions}

Figure 1: Distribution of surveyed vineyards in Maipo Valley Denomination of Origin and Maipo basin weather stations

Figure 2: Methodological flowchart: Assessing the baseline and projected composite viticultural suitability of the Maipo Valley

Figure 3: The baseline topographic, soil, land use and composite viticultural potential of the Maipo Valley

Figure 4: Projected composite viticultural suitability by climate grape maturity class under emissions scenarios A1B and B1 in three climate normal periods

Table 1: Topographic suitability class rankings used in determining the potential of the landscape to grow winegrapes

Table 2: Soil suitability class rankings used in categorizing the suitability of soil to winegrape cultivation

Table 3: Projected temperature changes under the seven individual downscaled Global Circulation Models utilized in this study in three climate normals

Table 4: Baseline and projected composite viticultural land area statistics by climate maturity group 